\title{
ETCH PROCESSING OF III-V NITRIDES
}

\author{
Charles R. Eddy, Jr. \\ Boston University \\ Electrical \& Computer Engineering Dept. \\ 8 Saint Mary's Street, Boston, MA 02215-2421
}

\section{Cite this article as: MRS Internet J. Nitride Semicond. Res. 4S1, G10.5(1999)}

\begin{abstract}
As III-V nitride devices advance in technological importance, a fundamental understanding of device processing techniques becomes essential. Recent works have exposed various aspects of etch processes. The most recent advances and the greatest remaining challenges in the etching of $\mathrm{GaN}$, AlN, and $\mathrm{InN}$ are reviewed. A more detailed presentation is given with respect to GaN high density plasma etching. In particular, the results of parametric and fundamental studies of GaN etching in a high density plasma are described. The effect of ion energy and mass on surface electronic properties is reported. Experimental results identify preferential sputtering as the leading cause of observed surface non-stoichiometry. This mechanism provides excellent surfaces for ohmic contacts to n-type GaN, but presents a major obstacle for Schottky contacts or ohmic contacts to p-type GaN. Chlorine-based discharges minimize this stoichiometry problem by improving the rate of gallium removal from the surface. In an effort to better understand the high density plasma etching process for GaN, in-situ mass spectrometry is employed to study the chlorine-based high density plasma etching process. Gallium chloride mass peaks were monitored in a highly surface sensitive geometry as a function of microwave power (ion flux), total pressure (neutral flux), and ion energy. Microwave power and pressure dependencies clearly demonstrate the importance of reactive ions in the etching of wide band gap materials. The ion energy dependence demonstrates the importance of adequate ion energy to promote a reasonable etch rate $(\geq 100-150 \mathrm{eV})$. The benefits of ion-assisted chemical etching are diminished for ion energies in excess of $350 \mathrm{~V}$, placing an upper limit to the useful ion energy range for etching $\mathrm{GaN}$. The impact of these results on device processing will be discussed and future needs identified.
\end{abstract}

\section{INTRODUCTION}

The family of nitride semiconductors has undergone amazing growth and development in the last decade and is now poised to play a pivotal role in a wide range of advanced semiconductor devices. This family, comprised of the binary semiconductors InN, GaN, and AlN and their ternaries, is now being applied in light emitting diodes that emit from UV to the amber regions of the visible electromagnetic spectrum and to blue lasers. Aside from these landmark optoelectronic device realizations, nitride semiconductors are also undergoing extensive research and development efforts for application in high frequency, high temperature, and high power microelectronic devices. In practically all of these applications, the ability to pattern the nitride semiconductor is required.

As a result of many of the properties that make nitride semiconductors attractive in the aforementioned electronic and optoelectronic device applications, they have proven notoriously difficult to etch. This situation has placed energetic pattern transfer processes in the lead for 
nitride device development. It has also placed some restriction on acceptable masking materials for lithography - with more robust silicon dioxide and nitride often being chosen over photoresist. These requirements for etch processing of the nitrides clearly differentiates them from silicon, gallium arsenide and indium phosphide, the only semiconductors with reasonably well understood etch processes. As a result, considerable research and development will be required to realize production-quality etch processes for the nitrides.

In this work, the progress in developing etch processes for the nitrides is reviewed and the remaining etch process issues are identified. The review starts with a brief overview of wet etching techniques and then moves on to cover the more prominent ion-assisted etching techniques. The first ion assisted technique addressed is the conventional reactive ion etching processes. The review then moves on to discuss the bulk of nitride etching efforts where high density plasmas have been employed. Also in this section, detailed results of experiments investigating the damage resulting from and the fundamentals of high density plasma etching will be discussed. The highlights of these efforts are then summarized and the most important remaining issues identified.

\section{WET ETCHING METHODS}

As a result of their high bond energies, group III nitrides typically are not etched by wet etching methods. The efforts to date are well reviewed in a recent chapter by Pearton and Shul[1]. Wet etchants are generally only successful on poor quality nitride films deposited by sputtering or reactive evaporation. For these poor quality films both acid and base solutions are moderately successful at elevated temperatures. If such films are first annealed to improve their quality, etch rates drop by up to an order of magnitude. For single crystal nitrides it is very difficult to find reliable, effective wet etchants. For single crystal $\mathrm{GaN}$ and $\mathrm{InN}$ there are no wet etchants that are effective under $80^{\circ} \mathrm{C}$. For $\mathrm{AlN}$, however, photoresist developer and strong $\mathrm{KOH}$ solutions are effective at lower temperatures.

Since standard wet etches are largely ineffective, there have been a number of efforts examining assisted wet etching techniques. The most successful has been photoelectrochemical etching of $\mathrm{n}-\mathrm{GaN}$ grown on SiC. A description of the apparatus is given elsewhere [2], but is basically electrochemical etching in $\mathrm{KOH}$ under broad area illumination from a $\mathrm{Hg}$ arc lamp. The above bandgap light creates electron-hole pairs that in $\mathrm{n}-\mathrm{GaN}$ provides a hole flux to the surface where the holes assist in the chemical attack. The technique is not effective for $\mathrm{p}-\mathrm{GaN}$ as holes are unable to reach the surface due to the specific band bending in the material [2]. Highly anisotropic, high rate $(>3000 \AA / \mathrm{min})$ etching is achieved at room temperature in $0.04 \mathrm{M} \mathrm{KOH}$ with $50 \mathrm{~mW} / \mathrm{cm}^{2}$ light intensity (measured at $365 \mathrm{~nm}$ ). The process becomes diffusion limited in these solutions for light intensities greater than $20 \mathrm{~mW} / \mathrm{cm}^{2}$ [3]. Very smooth surfaces are achievable (1.5nm roughness vs. $0.3 \mathrm{~nm}$ as-grown) with $0.02 \mathrm{M} \mathrm{KOH}$ solutions at $40 \mathrm{~mW} / \mathrm{cm}^{2}$ light intensities at $365 \mathrm{~nm}$. The smoothness is a very sensitive function of the molarity of the solution [4]. These same solutions have recently been used as a threading and mixed dislocation identification tool for counting low defect density $\mathrm{GaN}$ (such as lateral epitaxially overgrown films) with the same high degree of sensitivity on the molarity of the solution [5]. 


\section{DRY ETCHING METHODS}

\section{$\underline{\text { Reactive Ion Etching }}$}

Conventional reactive ion etching (RIE) using parallel plate electrodes and capacitively coupled $13.56 \mathrm{MHz}$ plasma generation power has long been the primary technique for pattern transfer in silicon and gallium arsenide device technologies. In these reactors the plasma density and energy of impinging ions on the substrate are tightly coupled with higher applied rf powers resulting in higher densities and energies. Low damage etch processing using RIE is possible in the $\mathrm{Si}$ and GaAs systems with low applied rf power levels. Despite the associated drop in density, etch rates remained reasonable due to the low binding energy of these semiconductors. In the nitrides, with their much higher binding energies, this is not the situation as a quick review of research efforts will show.

The results of a representative set of studies on RIE of the III-V nitrides are summarized in Table I. The bulk of RIE efforts have centered on the application of halogen chemistries (predominantly chlorine) and have involved high coupled rf powers[6-10]. This is consistent with higher plasma densities and high dc bias levels or ion energies. In all cases nitride etch rates are seen to increase monotonically with increasing rf power and decrease with increasing pressure - signifying the importance of the ion driven or physical component to the etch process. Demonstrated etch rates have maximum values of $\sim 1000 \AA$, with the notable exception of GaN in $\mathrm{Cl}_{2}$ chemistries. Most of these works have been performed with resist masks that were relatively thick in order to withstand the high ion energies used in processing. Under such conditions etch selectivities between the mask material and the nitride are low. These conditions are also likely to result in considerable surface damage to the nitride. Halogen-based chemistries give higher etch rates than methyl based chemistries, except for $\mathrm{InN}$, which is consistent with arsenide semiconductor processing observations. A final note, is that processing with Si-containing precursors can render the nitride surface Si-doped. This generates the need for post-etch processing to recover the original nitride surface properties.

Based upon these efforts, the application of RIE to pattern transfer processing in the III-V nitrides faces considerable difficulties. Primarily, the rates are very low prohibiting application to the etching of light emitting diode and laser diode structures due to the required depth of the etch. Furthermore, the high ion energies required to achieve even these modest rates have

Table I. Summary of select RIE efforts in the III-V nitrides.

\begin{tabular}{|c|c|c|c|c|c|}
\hline $\begin{array}{c}\text { Plasma } \\
\text { Chemistry }\end{array}$ & $\begin{array}{l}\text { Bias or } \\
\text { Power } \\
\text { Density }\end{array}$ & $\begin{array}{c}\text { Etch Rates } \\
{[\AA / \mathrm{min}]}\end{array}$ & $\begin{array}{l}\text { Masking } \\
\text { Material }\end{array}$ & Comments & Ref \\
\hline $\mathrm{CHF}_{3}$ & $100-500 \mathrm{~W}$ & $50-200(\mathrm{GaN})$ & Shipley 1813 & 6k-9k $\AA$ resist, 100 mTorr & 6 \\
\hline $\mathrm{C}_{2} \mathrm{ClF}_{5}$ & “ & “ & “ & “ & 6 \\
\hline $\mathrm{BCl}_{3}$ & $0.3-0.9 \mathrm{~W} / \mathrm{cm}^{2}$ & $150-730(\mathrm{AlGaN})$ & $\mathrm{Ni}$ & $\mathrm{AlGaN} / \mathrm{Ni}$ selectivity $=4 / 1$ & 7 \\
\hline $\mathrm{SiCl}_{4} / \mathrm{SiF}_{4}$ & $-400 \mathrm{~V}$ & $500(\mathrm{GaN})$ & & Smooth, anisotropic & 8 \\
\hline $\mathrm{Cl}_{2} / \mathrm{Ar}$ & $450 \mathrm{~W}$ & $\begin{array}{c}2800(\mathrm{GaN}) \\
200(\mathrm{AlN}) \\
200(\mathrm{InN})\end{array}$ & Resist & & 9 \\
\hline $\mathrm{CH}_{4} / \mathrm{H}_{2} / \mathrm{Ar}$ & $450 \mathrm{~W}$ & $\begin{array}{l}400(\mathrm{GaN}) \\
350(\mathrm{AlN}) \\
300(\mathrm{InN})\end{array}$ & Resist & & 9 \\
\hline $\mathrm{HBr} / \mathrm{H}_{2} / \mathrm{Ar}$ & $-400 \mathrm{~V}$ & $400-600(\mathrm{GaN})$ & $\begin{array}{c}\mathrm{AZ} 5214, \mathrm{Ni} / \\
\mathrm{SiO}_{2}\end{array}$ & & 10 \\
\hline
\end{tabular}


serious negative consequences for surface damage and for selectivities between mask and substrate and heterojunction layers. These consequences place substantial challenges to the application of RIE in nitride device processing.

\section{High Density Plasma Etching}

\section{$\underline{\text { General Overview of Efforts }}$}

High density plasma reactors have a significant advantage over the reactive ion etching reactors of the previous section - the ion density or plasma density can be de-coupled from the bias applied to the substrate. This permits the high ion flux densities that data from RIE experiments have shown enhances nitride etch rates, but with low, adjustable ion energies $(>20$ $\mathrm{eV})$. This characteristic enables higher selectivity in the etch process and lower damage levels to the semiconductor surface while maintaining reasonable etch rates.

The family of high density plasma reactors essentially consists of electron cyclotron resonance (ECR) microwave plasma sources and inductively coupled plasma (ICP) sources. However, it is appropriate to include magnetically enhance reactive ion etching (MERIE) systems because of the similarities in the discharges in terms of plasma density.

The efforts to etch III-V nitrides using high density plasma sources are summarized in Table II. As can be seen, the etch rates achieved with these methods is nearly an order of magnitude higher than in conventional RIE methods. The bulk of these efforts have involved halogen based chemistries including chlorine- [11-17], iodine- [18], and bromine-based [14,17] chemistries. There have also been efforts in mixed halogen chemistries such as $\mathrm{ICl}$ [19] and $\mathrm{CCl}_{2} \mathrm{~F}_{2}$ [17]. Based upon successful application to the etching of other III-V compound semiconductors, methyl-based chemistries have also been investigated [14,17]. The fastest etch rates are generally achieved at high microwave powers in halogen based chemistries. The ICl chemistry has produced the fastest reported etch rates for all three nitrides: $1.3 \mu \mathrm{m} / \mathrm{min}$ for $\mathrm{GaN}$, $1.15 \mu \mathrm{m} / \mathrm{min}$ for InN, and $7000 \AA / \mathrm{min}$ for AlN (notably, at a bias of $-275 \mathrm{~V}$ ).

Because of the ion driven nature of the etch process for the nitrides achievement of vertical sidewalls in etched features is mostly dependent on the robustness of the mask material. When the mask is sufficiently robust to the etch process, perfectly vertical sidewalls are achieved. When the mask is eroded by the etch process the features are overcut and critical dimensions are compromised. A remaining challenge is the introduction of a controlled degree of isotropy to the process. This is important in the fabrication of field effect and bipolar junction devices which require conformal, uniform metal gate deposition over etch steps to avoid a reduction in the breakdown voltage of the device.

High selectivity between the nitrides is important in the processing of heterojunction structures used in lasers, field effect, and bipolar junction transistor devices. The maximum

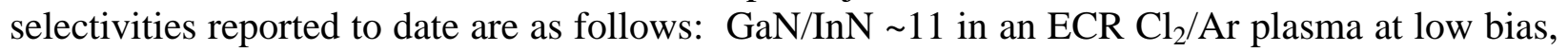
GaN/AlN $\sim 6$ in an ECR ICl/Ar plasma at high bias, and InN/GaN $\sim 6.5$ in an $\mathrm{ECR} \mathrm{CH}_{4} / \mathrm{H}_{2} / \mathrm{Ar}$ plasma at low bias[19]. These levels are generally 5-10 times smaller than desired for heterojunction device processing. Thus, improved etch selectivities are another area in need of substantial research and development efforts. 
Table II. Summary of select High Density Plasma Etching Efforts in the III-V Nitrides.

\begin{tabular}{|c|c|c|c|c|c|}
\hline Chemistry & Technique & $\begin{array}{c}\text { Etch Rate } \\
(\AA / \text { min })\end{array}$ & $\begin{array}{l}\text { Source Power } \\
\text { (Watts) }\end{array}$ & $\begin{array}{c}\text { Bias } \\
\text { (Volts) }\end{array}$ & $\overline{\text { Ref }}$ \\
\hline $\mathrm{BCl}_{3}$ & MERIE & $3500(\mathrm{GaN})$ & $0.5 \mathrm{~W} / \mathrm{cm}^{2}$ & -75 & 11 \\
\hline $\mathrm{SiCl}_{4}$ & ECR & $960(\mathrm{GaN})$ & $300 \mathrm{~W}$ & -280 & 12 \\
\hline $\mathrm{Cl}_{2}$ & ICP & $\begin{array}{l}4000(\mathrm{GaN}) \\
2000(\mathrm{AlN}) \\
2200(\mathrm{InN})\end{array}$ & $500 W$ & -250 & 13 \\
\hline $\mathrm{Cl}_{2}$ & ICP & $\begin{array}{l}1200(\mathrm{GaN}) \\
200(\mathrm{AlN}) \\
4800(\mathrm{InN})\end{array}$ & $\begin{array}{l}1500 \mathrm{~W} \\
1500 \mathrm{~W} \\
1000 \mathrm{~W}\end{array}$ & -100 & 14 \\
\hline $\mathrm{BCl}_{3}$ & ICP & $\begin{array}{l}3000(\mathrm{GaN}) \\
2200(\mathrm{AlN}) \\
2600(\mathrm{InN})\end{array}$ & $500 \mathrm{~W}$ & -250 & 13 \\
\hline $\mathrm{Cl}_{2} / \mathrm{BCl}_{3}$ & ICP & $8500(\mathrm{GaN})$ & $600 \mathrm{~W}$ & -120 & 15 \\
\hline $\mathrm{Cl}_{2} / \mathrm{CH}_{4} / \mathrm{H}_{2}$ & ECR & $\begin{array}{c}2340(\mathrm{GaN}) \\
960(\mathrm{AlN}) \\
2300(\mathrm{InN})\end{array}$ & $850 \mathrm{~W}\left(170^{\circ} \mathrm{C}\right)$ & -180 & 16 \\
\hline $\mathrm{HI} / \mathrm{H}_{2}$ & ECR & $\begin{array}{l}1100(\mathrm{GaN}) \\
1250(\mathrm{AlN}) \\
1000(\mathrm{InN})\end{array}$ & 1000W & -150 & 18 \\
\hline $\mathrm{HBr} / \mathrm{H}_{2}$ & ECR & $\begin{array}{l}900(\mathrm{GaN}) \\
700(\mathrm{AlN}) \\
200(\mathrm{InN})\end{array}$ & $1000 \mathrm{~W}$ & -150 & 18 \\
\hline $\mathrm{ICl}$ & ECR & $\begin{array}{c}13000(\mathrm{GaN}) \\
7000(\mathrm{AlN}) \\
11500(\mathrm{InN})\end{array}$ & $1000 \mathrm{~W}$ & -275 & 19 \\
\hline $\mathrm{CCl}_{2} \mathrm{~F}_{2}$ & ECR & $\begin{array}{c}300(\mathrm{GaN}) \\
90(\mathrm{AlN}) \\
90(\mathrm{InN})\end{array}$ & $200 \mathrm{~W}$ & -250 & 17 \\
\hline $\mathrm{CH}_{4} / \mathrm{H}_{2}$ & ECR & $\begin{array}{l}75(\mathrm{GaN}) \\
25(\mathrm{AlN}) \\
100(\mathrm{InN})\end{array}$ & $200 \mathrm{~W}$ & -300 & 17 \\
\hline $\mathrm{CH}_{4} / \mathrm{H}_{2}$ & ICP & $\begin{array}{c}1250(\mathrm{GaN}) \\
200(\mathrm{AlN}) \\
1250(\mathrm{InN})\end{array}$ & $500 \mathrm{~W}$ & -225 & 14 \\
\hline
\end{tabular}

\section{Damage Studies}

In addition to the above considerations, one of the most critical figures of merit for etch processing of devices is the damage imparted to the remaining semiconductor. To date, most reports on etch damage in the III-V nitrides have centered on topographic or stoichiometric changes imparted to the surface [13,20-23]. In these representative reports, smooth etched surfaces are identified as generally achievable, with the exception of "etch pit" formation on the surfaces of nitride films grown on basal plane sapphire [13]. Smooth sidewall surfaces are also reported to be contingent upon a robust mask - erosion of the mask edges leads to striations in the sidewall in these high fidelity processes [13].

Although such damage reports are important to the development of low damage processes for the nitrides, it is the effect of etch processing on the electronic properties of nitride surfaces that is essential to the creation of high quality devices. Despite this importance there have been far fewer reports on electronic damage [24-29]. The general conclusions from these efforts are that 
high density plasma etching renders the n-type $\mathrm{GaN}$ surface less conductive (due primarily to mobility reduction) and semi-insulating $\mathrm{GaN}$ surfaces n-type conducting and that the degree of conduction enhancement or degradation is a strong function of incident ion energy and mass. This result is often beneficial to ohmic contacts to n-type $\mathrm{GaN}$, but presents a challenge for reproducible ohmic contacts to p-type $\mathrm{GaN}$ or Schottky contacts to either extrinsic type. This result is consistent in InN-based semiconductors where ion energies > $300 \mathrm{eV}$ resulted in a reduction in carrier concentrations - presumably the result of deep trap introduction [27]. As with other III-V compound semiconductors hydrogen has been shown to passivate shallow dopants in the nitrides [30,31].

We have performed detailed experiments on ECR plasma etching damage in n-type $\mathrm{GaN}$ (Sidoped to mid $10^{18} \mathrm{~cm}^{-3}$ ) and highly resistive GaN films grown by MOCVD on sapphire [29]. The $\mathrm{GaN}$ wafers used in this study were grown by metal organic chemical vapor deposition (MOCVD) on c-plane (0001) oriented sapphire substrates. The surface of the sample was smooth ( $\sim 5 \mathrm{~nm}$ rms roughness by atomic force microscopy) and the thickness of the layers was $2-3 \mu \mathrm{m}$. The wafers were cut into $\sim 0.4 \mathrm{~cm}^{2}$ samples and the individual samples were evaluated using Hall measurements before and after exposure to the etching environment. Electron beam evaporated W/10\% Ti alloy thin films deposited on the corners of the samples served as both ohmic contacts and as etch masks. Semi-insulating GaN film resistances were determined by I-V measurements using removable liquid $\mathrm{Ga} / \mathrm{In}$ eutectic contacts. Etch depths were measured with a Tencor AlphaStep 250 stylus profilometer.

All plasma etching was performed in an electron cyclotron resonance microwave plasma reactive ion etching system described previously [32]. In these experiments, the total pressure was held at $1 \mathrm{mT}$ Torr while total flows of $12.8 \mathrm{sccm}, 9.6 \mathrm{sccm}, 6.8 \mathrm{sccm}$ and $9.0 \mathrm{sccm}$ were used for $\mathrm{CH}_{4} / \mathrm{H}_{2} / \mathrm{Ar}$ (2.8/6.8/3.2 flow fractions), $\mathrm{CH}_{4} / \mathrm{H}_{2}$ (2.8/6.8), $\mathrm{H}_{2}$ and $\mathrm{Cl}_{2}$ chemistries, respectively. Microwave powers of $300-400 \mathrm{~W}$ and $200 \mathrm{~W}$ were used for hydrogen-containing and chorine-based chemistries, respectively. The capacitively coupled, rf-induced dc bias level of the substrate platen ranged from $-150 \mathrm{~V}$ to $-400 \mathrm{~V}$ (corresponding to rf power densities from $0.8 \mathrm{~W} / \mathrm{cm}^{2}$ to $3.4 \mathrm{~W} / \mathrm{cm}^{2}$ ) for all of the studies performed here. The substrates were placed 32 $\mathrm{cm}$ downstream of the position of the electron cyclotron resonance condition, defined by the onaxis location of the $875 \mathrm{G}$ magnetic field intensity contour.

Rapid thermal annealing experiments were performed to evaluate the response of electrical parameters to annealing treatments. In these experiments, the wafer is placed face down on a $\mathrm{Si}$ wafer with the GaN surface in contact with the smooth Si surface. Annealing was performed in flowing $\mathrm{N}_{2}$ gas. The sample was first annealed at $400^{\circ} \mathrm{C}$ for $30 \mathrm{sec}$ and then a room temperature Hall measurement was performed. The annealing was continued at higher temperatures in $100^{\circ} \mathrm{C}$ increments, each of $30 \mathrm{sec}$ duration. After each anneal the electrical parameters were determined.

In these efforts, we've found that 'etching' in inert gas plasmas renders the surface of n-type films more resistive and that the degree of resistivity is dependent on ion energy and mass heavier ions (Ar) at higher energies $(400 \mathrm{eV})$ resulting in the most resistive films. The resistivity increase is largely attributed to a drastic decrease in the mobility. Similar observations are made on $\mathrm{GaN}$ films etched in $\mathrm{CH}_{4} / \mathrm{H}_{2} / \mathrm{Ar}$ ECR plasmas. Films etched at $300 \mathrm{eV}$ in hydrogen shown only modest increases in resistivity, and decreases in mobility. Films etched in $\mathrm{Cl}_{2}$ ECR plasmas etched at the fastest rates $(>2000 \AA / \mathrm{min})$ and showed no change in the surface electrical properties. Supporting results of surface stoichiometry (Auger Electron Spectroscopy) and topography (Atomic Force Microscopy and Scanning Electron Microscopy) show that heavily damaged surfaces are well decorated with 'etch pits' (Figure 1) and are gallium rich (with preetch Ga: $\mathrm{N}$ ratios of 2 and post-etch ratios of 3.2). This damage could be annealed away with rapid thermal anneals of $120 \mathrm{sec}$ duration at temperatures as low as $450^{\circ} \mathrm{C}$. These observations 


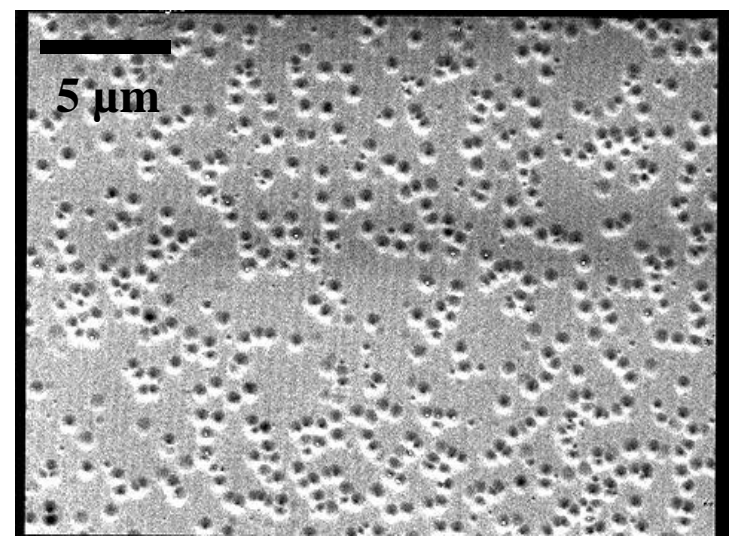

Figure 1. SEM micrograph of GaN surface morphology after 20 min. exposure to $150 \mathrm{eV}$ Ar ions.

support a combination of preferential sputtering and compensating defects. Preferential sputtering increases the depth of disorder to $\sim 2000 \AA$. The addition of a strong chemical component, as in $\mathrm{Cl}_{2}$ etching, reduces the disorder by removing it at a rate comparable to its introduction leaving the surface effectively undamaged. Similar dependencies on etch gas, ion mass, and ion energy are observed in highly resistive films (undoped, $\mathrm{R}_{\mathrm{o}}>10^{8} \Omega$ ) except that the surfaces were rendered more n-type conducting.

\section{Fundamentals of Nitride Etching Studies}

We've also performed preliminary studies investigating the fundamentals of etching of $\mathrm{GaN}$ in an effort to understand the etching process in terms of process conditions most suited to ionassisted etching at minimal damage levels. These studies have involved the use of mass spectrometric sampling through the substrate platen with and without the substrate present. Studies without the substrate were performed to evaluate the make-up of the incident plasma flux as a function of process conditions (pressure and microwave power) [33]. Studies with unpatterned GaN films (grown by MOCVD on sapphire) were performed to evaluate the rate of etch product formation as a function of variations in the plasma flux and the incident ion energy. The sampling technique has been shown to be extremely sensitive to the surface chemistry and, therefore, provides an unambiguous sampling of surface chemistry through monitoring of etch products that evolve from the surface $[34,35]$.

The $\mathrm{GaCl}_{2}$ etch products at $139\left({ }^{69} \mathrm{Ga}^{35} \mathrm{Cl}_{2}\right), 141\left({ }^{69} \mathrm{Ga}^{35} \mathrm{Cl}^{37} \mathrm{Cl}\right.$ and $\left.{ }^{71} \mathrm{Ga}^{35} \mathrm{Cl}_{2}\right), 143$ $\left({ }^{71} \mathrm{Ga}^{35} \mathrm{Cl}^{37} \mathrm{Cl},{ }^{69} \mathrm{Ga}^{37} \mathrm{Cl}\right)$, and $145\left({ }^{71} \mathrm{Ga}^{37} \mathrm{Cl}_{2}\right)$ are used to monitor the etch product formation rate as a function of changes in the plasma/surface interaction region. As microwave power is increased from 300-600 W, Figure 2, we see a monotonic increase in the mass peak intensities of the etch products with a particular jump between 400 and $450 \mathrm{~W}$. Flux characterization

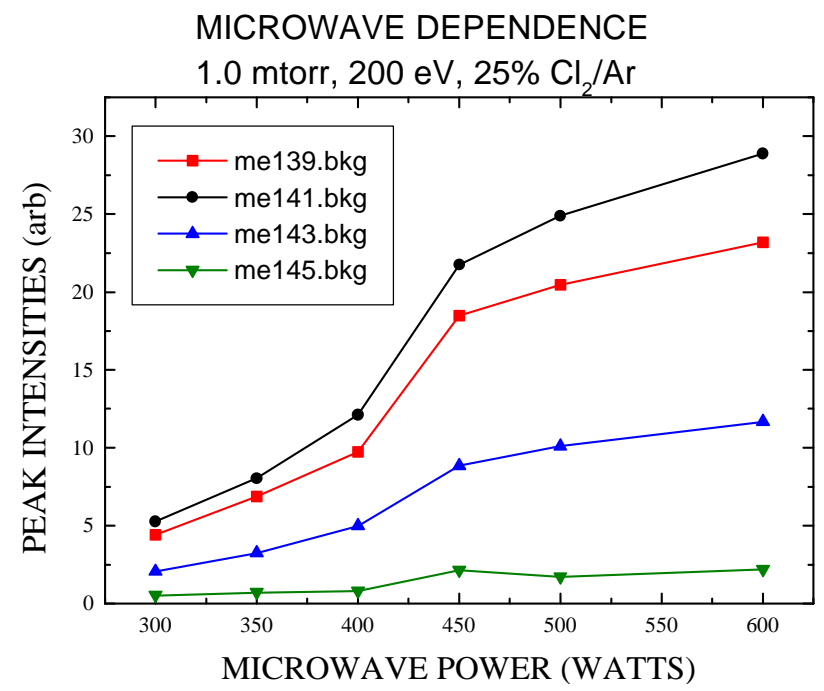

Figure 2. Variation in etch product mass intensities with coupled microwave power. measurements show that for $>300 \mathrm{~W}$ microwave power the flux is nearly fully dissociated, consistent with other reports. For $>400 \mathrm{~W}$ microwave power, the flux is dominated by $\mathrm{Cl}^{+}$and $\mathrm{Ar}^{+}$. Figure 3 shows the dependence of etch product formation on the process pressure. We see a dramatic decrease in the mass peak intensities of the etch products as pressure is increased from 0.25 to 2 mTorr. Over this same pressure range, flux characterizations show that the ion fraction of the flux drops rapidly to background levels at 2 mTorr as the pressure is increased and that neutral species rise monotonically over this pressure range with $\mathrm{Cl}_{2}$ and $\mathrm{Ar}$ domination for pressures $>1 \mathrm{mTorr}$. 


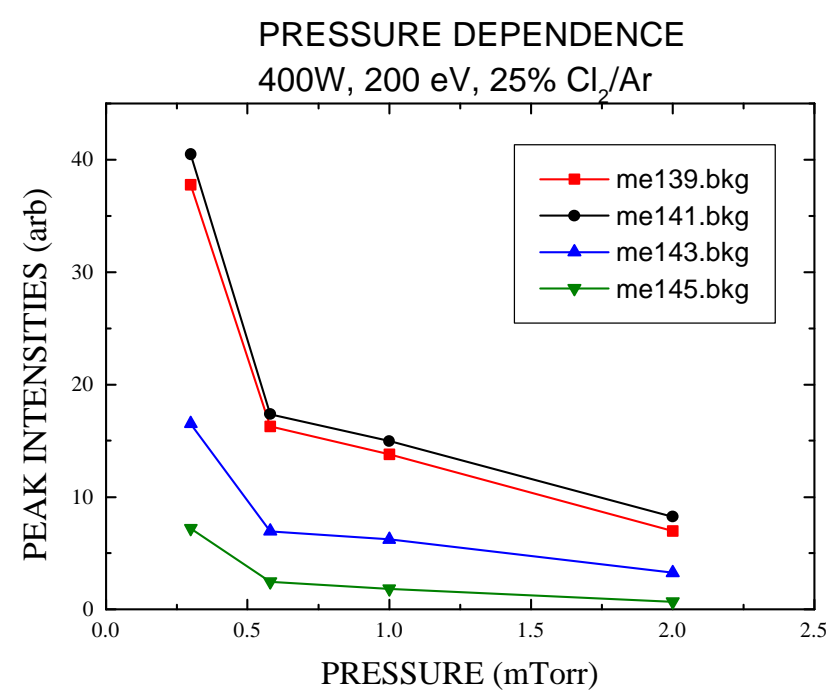

Figure 3. Variation in etch product mass intensities with process pressure.
Taken together, these observations with variations in process conditions indicate a clear need for a high ion and atomic chlorine fluxes at the substrate to promote reasonable etch rates, this requires process conditions of high microwave powers and low process pressures. These requirements should be met with care, however, as they will reduce selectivity. The pressure requirement is well aligned with the highly anisotropic nature of etch processing at these pressures due to increased directionality of incident ions. Both requirements further support high density plasma tools as the tool of choice for nitride etch processing.

The critical parametric dependence for understanding the driving force behind surface chemistry in these etch processes is the dependence of etch product formation rate on incident ion energy. Figure 4 shows the dependence of the $\mathrm{GaCl}_{2}$ mass peak intensities on incident ion energy, as determined by the level of the capacitively coupled rf bias power. As can be seen in the figure, there is effectively no etching of $\mathrm{GaN}$ for ion energies up to $75-100 \mathrm{eV}$. Above that level, the etch product formation rate begins to slowly increase up to energies of $200 \mathrm{eV}$, indicative of ion-assisted product formation. This ion-assist is substantially enhanced for ion energies in the $200-350 \mathrm{eV}$ range as

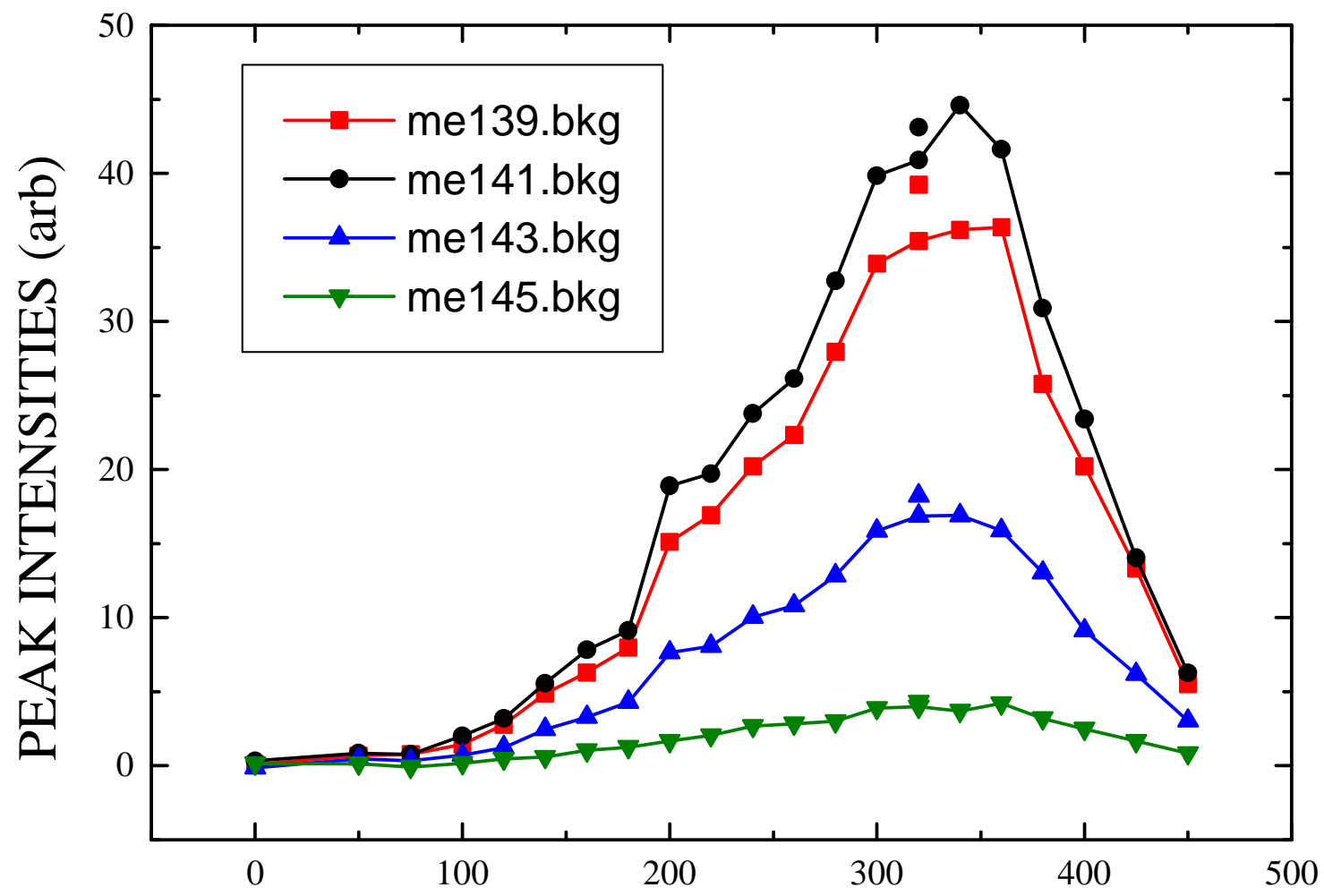

Figure 4. Variation in etch product mass intensities with substrate bias. 
the product mass peak intensities increase rapidly over this range. For ion energies greater than $350 \mathrm{eV}$ there is a considerable decrease in the product mass peak intensities, almost to background levels by $450 \mathrm{eV}$. Over this same range of energies, we have seen and others have shown that the GaN etch rate continues to increase. Combining these observations, we see that at $350 \mathrm{eV}$ the etch process transitions from the desired ion-assisted chemistry to physical sputtering. The best results are therefore expected when the ion energy is in the range from 150$350 \mathrm{eV}$. Excellent anisotropy can be expected over this entire range, while the higher end of this range will give faster etch rates with poor selectivity and high damage levels and the lower end of the range will give better selectivities and lower damage levels.

\section{SUMMARY \& FUTURE DIRECTIONS}

Various plasma-based etching techniques for III-V nitrides have been reviewed. Conventional reactive ion etching techniques using a capacitively-coupled parallel plate geometry are capable of etching the nitrides, but etch rates are very low even at relatively high ion energies $(400 \mathrm{eV})$. This situation has serious negative implications on selectivity and damage, but demonstrates the importance of ions to the etching process in the III-V nitrides. As a whole, high density plasma etching has many advantages for etch processing of the nitrides. Etch rates approaching $1 \mu \mathrm{m} / \mathrm{min}$ are being realized in chlorine-based chemistries. Perfect anisotropy is possible due to the strong ion dependence of the etching mechanism. The limit on anisotropy is the robustness of the mask material, if the mask erodes the profiles will be overcut. A remaining challenge is the introduction of some degree of controlled isotropy to the process for device technologies requiring rounded trench bottoms. Etch selectivity between the nitrides is quickly becoming a daunting issue, also a result of the strong ion dependence of the etching mechanism. Maximum selectivities are 6-10 and higher selectivities are desired for ease of processing heterojunction devices, particularly the microelectronic versions. Etch damage to GaN surfaces is strongly influenced by ion energy and mass. This is partially attributed to preferential sputtering of nitrogen. The addition of a chemical component to the etch greatly reduces the effect by rapidly removing the residual gallium from the surface. Fundamental studies in high density plasma etching have shown that $\mathrm{GaCl}$ product formation, presumably the limiter - although the true limitation is likely the breaking of the $\mathrm{GaN}$ bond to permit formation of $\mathrm{GaCl}$ - is most efficient for $\mathrm{Cl}, \mathrm{Cl}^{+}$dominated plasma fluxes to the substrate. This is consistent with high plasma powers and low pressures. These studies have also shown that the most effective ion-assisted etching is for incident ion energies in the $150-350 \mathrm{eV}$ range.

\section{ACKNOWLEDGEMENTS}

The author wishes to acknowledge the efforts of Drs. Bela Molnar, Darrin Leonhardt, Vasgen Shamamian, and James Butler for their substantial efforts in the damage and fundamental experiments reported here. I also wish to acknowledge the support of the Office of Naval Research. 


\section{REFERENCES}

1 S.J. Pearton and R.J. Shul in Gallium Nitride I, J. Pankove and T.D. Moustakas Eds., Semiconductor and Semimetals Series, Vol. 50, P. 103, Academic Press, New York, NY (1998).

2 C. Youtsey, I. Adesida and G. Bulman, Electronics Lett. 33, 245 (1997).

3 C. Youtsey, I. Adesida and G. Bulman, Appl. Phys. Lett. 71, 2151 (1997).

4 C. Youtsey, I. Adesida, L.T. Romano and G. Bulman, Appl. Phys. Lett. 72, 560 (1998).

5 C.Youtsey, L.T. Romano and I. Adesida, Appl. Phys. Lett. 73, 797 (1998).

6 H. Lee, D.B. Oberman and J.S. Harris, Jr., Appl. Phys. Lett. 67, 1754 (1995).

7 W.C. Hughes, W.H. Roland, Jr., M.A.L. Johnson, J.W. Cook, Jr. and J.F. Schetzina, in Gallium Nitride \& Related Materials, F.A. Ponce, R.D. Dupuis, S. Nakamura and J.A. Edmond eds., MRS Proc. Vol. 395, p. 757, Materials Research Society, Pittsburgh, PA (1996).

8 I. Adesida, A. Mahajan, E. Andideh, M. Asif Khan, D.T. Olsen and J.N. Kuznia, Appl. Phys. Lett. 63, 2777(1993).

9 C.B. Vartuli, J.D. MacKenzie, J.W. Lee, C.R. Abernathy, S.J. Pearton and R.J. Shul, J. Appl. Phys. 80, 3705 (1996).

10 A.T. Ping, I. Adesida, M. Asif Khan and J.N. Kuznia, Electronics Lett. 30, 1895 (1994).

11 G.F. McLane, L. Casas, S.J. Pearton and C.R. Abernathy, Appl. Phys. Lett. 66, 3328 (1995).

12 L. Zhang, J. Ramer, J. Brown, K. Zheng, L.F. Lester and S.D. Hersee, Appl. Phys. Lett. 68, 367 (1996).

13 R.J. Shul, C.G. Willison, M.M. Bridges, J. Han, J.W. Lee, S.J. Pearton, C.R. Abernathy, J.D. MacKenzie, S.M. Donovan, L. Zhang, and L.F. Lester, J. Vac. Sci. Technol. A 16, 1621 (1998).

14 H. Cho, C.B. Vartuli, S.M. Donovan, C.R. Abernathy, S.J. Pearton, R.J. Shul, C. Constantine, J. Vac. Sci. Technol. A 16, 1631 (1998).

15 Y.H. Lee, H.S. Kim, G.Y. Yeom, J.W. Lee, M.C. Yoo and T.I. Kim, J. Vac. Sci. Technol. A 16, 1478 (1998).

16 R.J. Shul, S.P. Kilicoyne, M. Hagerott Crawford, J.E. Parmeter, C.B. Vartuli, C.R. Abernathy and S.J. Pearton, Appl. Phys. Lett. 66, 1761 (1995).

17 S.J. Pearton, C.R. Abernathy and F. Ren, J. Vac. Sci. Technol. A. 11, 1772 (1993).

18 S.J. Pearton, C.R. Abernathy and C.B. Vartuli, Electronics Lett. 30, 1985 (1994).

19 C.B. Vartuli, S.J. Pearton, J.D. Mackenzie, C.R. Abernathy and R.J. Shul, J. Electrochem. Soc. 143, L246 (1996).

20 S.J. Pearton, C.R. Abernathy, F. Ren and J.R.. Lothian, J. Appl. Phys. 76, 1210 (1994).

21 G.F. McLane, S.J. Pearton and C.R. Abernathy, in Wide Bandgap Semiconductors And Devices, PV 95-21, p. 204, The Electrochemical Society Proceedings, Pennington, NJ (1995).

22 R.J. Shul, A.J. Howard, S.J. Pearton, C.R. Abernathy and C.B. Vartuli, in Wide Bandgap Semiconductors And Devices, PV 95-21, p. 217, The Electrochemical Society Proceedings, Pennington, NJ (1995).

23 R.J. Shul, A.J. Howard, S.P. Kilcoyne, S.J. Pearton, C.R. Abernathy, C.B. Vartuli, P.A. Barnes and M.J. Bozack, in Proceedings $22^{\text {nd }}$ SOTAPOCS, PV 95-6, p. 209, The Electrochemical Society Proceedings, Pennington, NJ (1995).

24 C.R. Eddy, Jr. and B. Molnar in Gallium Nitride \& Related Materials, F.A. Ponce, R.D. Dupuis, S. Nakamura And J.A. Edmond Eds., MRS Proc. Vol. 395, p. 745, Materials Research Society, Pittsburgh, PA (1996).

25 B. Molnar, C.R. Eddy, Jr. and K. Doverspike, J. Appl. Phys. 78, 6132 (1995).

26 A.T. Ping, A.C. Schmitz, I. Adesida, M. Asif Khan, Q. Chen and J.W. Yang, J. Electron. Mater. 26, 266 (1997). 
27 S.J. Pearton, J.W. Lee, J.D. MacKenzie, C.R. Abernathy and R.J. Shul, Appl. Phys. Lett. 67, 2329 (1995).

28 H.Ishikawa, S. Kobayashi, Y. Koide, S. Yamasaki, S. Nagai, J. Umezaki,M. Koike and M. Murakami, J. Appl. Phys. 81, 1315 (1997).

29 C.R. Eddy, Jr. and B. Molnar, to appear in J. Electron. Mater., March 1999 issue.

30 M.S. Brandt, N.M. Johnson, R.J. Molnar, R. Singh and T.D. Moustakas, Appl. Phys. Lett. 64, 2264 (1994).

31 S. Nakamura, T. Mukai, M. Senoh and N. Iwasa, Jpn. J. Appl. Phys. 31, L139 (1992).

32 C.R. Eddy, Jr., E.A. Dobisz, J.R. Meyer and C.A. Hoffman, J. Vac. Sci. Technol. A 11, p. 1763 (1993)

33 C.R. Eddy, Jr., D. Leonhardt, S.R. Douglass, B.D. Thoms and J.E. Butler, J. Vac. Sci. Technol. A 17, 38 (1999).

34 C.R. Eddy, Jr., O.J. Glembocki, D. Leonhardt, V.A. Shamamian, R.T. Holm, B.D. Thoms, J.E. Butler, and S.W. Pang, J. Electron. Mater. 26, 1320 (1997).

35 D. Leonhardt, C.R. Eddy, Jr., V.A. Shamamian, R.T. Holm, O.J. Glembocki and J. E. Butler, J. Vac. Sci. Technol. A 16, 1547 (1998). 